\title{
Comments on Whiley Legionella Risk Management and Control in Potable Water Systems: Argument for the Abolishment of Routine Testing. Int. J. Environ. Res. Public Health 2017, 14, 12
}

\author{
Samuel Collins * and Jimmy Walker \\ Biosafety, Air and Water Microbiology Group, National Infection Service, Public Health England, \\ Salisbury SP4 0JG, UK; Jimmy.Walker@phe.gov.uk \\ * Correspondence: Samuel.collins@phe.gov.uk; Tel.: +44-19-8061-2586 \\ Academic Editor: Paul B. Tchounwou \\ Received: 4 January 2017; Accepted: 11 January 2017; Published: 21 January 2017
}

\begin{abstract}
In their recent article, Whiley makes an interesting case for the abolishment of routine testing in Legionella risk management and control plans. Here, we present our views regarding this suggestion, drawing upon our own experiences in the UK. We urge caution against the removal of routine monitoring from guidelines due to the impending public health risks that would result.
\end{abstract}

Keywords: Legionella; Legionnaires' disease; routine testing

We read with great interest the article by Whiley entitled 'Legionella Risk Management and Control in Potable Water Systems: Argument for the Abolishment of Routine Testing'. The author correctly highlights a number of issues that hamper the ability to define the public health risk from water systems contaminated with Legionella. Among these issues are the drawbacks associated with the current ISO 11731 'gold-standard' culture method, which include an inability to detect viable but nonculturable (VBNC) cells (the importance of VBNC cells in water systems as well as in infection and disease remains undefined [1]) and high inter- and intra-laboratory variability. We think that there is an argument for improved (cultivation-independent) detection methods that address these issues, enabling accurate enumeration and differentiation of living cells from dead cells from VBNC. As we understand more about the phylogenetic diversity of strains infecting humans [2], perhaps there is an argument for detection strategies targeted to those species, subtypes, or sequence types of Legionella known to cause the majority of diseases. Improved detection methods would improve our understanding of the survival of Legionella in potable water systems, inform future control measures, and provide more robust data for quantitative microbial risk assessment models.

The author states that routine testing of potable water systems for Legionella should be abolished from all guidelines and an emphasis placed on maintaining control measures. However, we advise caution against the wholesale implementation of this advice. We agree that the priority in any potable water system must be to establish and monitor appropriate control regimes highlighted in guidance documents that limit both the potential for Legionella to grow and its dissemination. Indeed, risk assessing control strategies forms the basis for many guidance documents worldwide, including the UK Health and Safety Executive Approved Code of Practice L8 [3] and associated technical guidance, the new ASHRAE guidelines [4], and the EWGLI (now ESGLI) technical guidelines [5]. As the author states, an overreliance on routine sampling results (which we appreciate only represent a snapshot in time) can induce a false sense of security [6]. However, so too can an overreliance on control measures alone. To illustrate this point over the past year, we have investigated three potable water systems epidemiologically linked with separate clusters and cases of Legionnaires' disease (LD). In all systems, 
control measures (e.g., temperature, and flow) were within recommended parameters and monitored as per national guidelines. However, extensive Legionella colonisation was present in key areas, notably where hot and cold water was mixed, e.g., post-thermostatic mixing valves and showers (unpublished data). Colonisation and risk were only identified by epidemiological data, i.e., when cases of LD were reported. Routine testing at these critical control points would have given an early warning and may have prevented these cases from occurring. The availability of planned routine sampling results can also prove very useful in public health investigations of $\mathrm{LD}$, where the colonisation history of a system under investigation (i.e., epidemiologically linked to cases) can help focus investigations and pin-point sources more readily.

The author makes reference to health-care facilities where reducing the exposure of vulnerable individuals is a key priority. Like many potable water systems, a number of hospitals in the UK are colonised with Legionella, but not all. It may be a false assumption that Legionella are ubiquitous in all potable water systems. For most UK hospitals, a zero-tolerance approach to Legionella is based on the assumption that there is no known safe level of Legionella and that remedial actions are therefore implemented at the detection of any concentration of Legionella [7]. Unlike current Centers for Disease Control and Prevention (CDC) recommendations [8], routine testing plays a crucial role in the water safety plan approach to managing these healthcare systems, proactively identifying risk and offering an additional layer of security to prevent even a single case of LD occurring. This approach, combined with clinical surveillance, has been shown to be effective in identifying and reducing cases of nosocomial LD [9]. It is unlikely that routine testing would be stopped in UK health-care facilities, particularly in systems known to be colonised, as testing provides a means whereby the effectiveness of control regimes can be measured. As Whiley pointed out, there may be an underestimation of the true concentration of Legionella in a sample and the variability of the test methods; however, it is logical to assume that the higher the concentration of Legionella present in a system the greater the potential for transmission and exposure. An increase in the concentration of Legionella should therefore be indicative of a potential problem and be investigated without delay. Moreover, the cost of routine testing and system-wide control measures needs to be carefully balanced against the use of alternative local approaches to protect high risk populations such as point-of-use filters, which, if used permanently, can be costly and may unknowingly introduce infection control risks themselves [10].

Even with the well acknowledged limitations of Legionella monitoring, surely the safest approach is to combine risk assessment, control measures (including meticulous monitoring), and routine water testing. Routine testing should be implemented on a system-by-system basis, informed by the risk assessment to reduce inappropriate or meaningless testing and expenditure and take into account the history of the system, the control measures, the previous test results, the population at risk, etc. The absence and detection of low concentrations of Legionella by culture (or by other analytical methods) combined with verified control measures are the ultimate reassurances that the microbiological risk has been managed appropriately. After all, cases of LD do not tend to be linked to systems where Legionella has not been detected $[9,11,12]$.

Given the controversies and multiple uncertainties in the Legionella field, particularly with regard to water system risk assessment and control, there is an urgent need for better and more robust studies to inform future control policies, particularly in light of a global rising incidence of LD and an increasingly older and immunocompromised population.

Acknowledgments: The views expressed in this article are those of the authors and not necessarily those of Public Health England.

Author Contributions: Samuel Collins and Jimmy Walker wrote the paper.

Conflicts of Interest: The authors declare no conflict of interest. 


\section{References}

1. Kirschner, A.K. Determination of viable Legionellae in engineered water systems: Do we find what we are looking for? Water Res. 2016, 93, 276-288. [CrossRef] [PubMed]

2. David, S.; Rusniok, C.; Mentasti, M.; Gomez-Valero, L.; Harris, S.R.; Lechat, P.; Lees, J.; Ginevra, C.; Glaser, P.; Ma, L.; et al. Multiple major disease-associated clones of Legionella pneumophila have emerged recently and independently. Genome Res. 2016, 26, 1555-1564. [CrossRef] [PubMed]

3. Health and Safety Executive. Legionnaires' Disease-The Control of Legionella Bacteria in Water Systems, 4th ed; HSE Books: London, UK, 2013.

4. American Society of Heating Refrigerating and Air-Conditioning Engineers (ASHRAE). Standard 188-2015 Legionellosis: Risk Management for Building Water Systems; ASHRAE: Atlanta, GA, USA, 2015.

5. European Working Group for Legionella Infections (EWGLI). EWGLI Technical Guidelines for the Investigation, Control and Prevention of Travel Associated Legionnaires' Disease. 2011. Available online: http://ecdc.europa.eu/en/healthtopics/legionnaires_disease/ELDSNet/Documents/EWGLITechnical-Guidelines.pdf (accessed on 16 January 2017).

6. Decker, B.K.; Clancy, C.J. Culture positivity and bacterial burden thresholds for Legionella in hospital water: Proceed with caution. Am. J. Infect. Control 2016, 44, 730. [CrossRef] [PubMed]

7. Department of Health. Health Technical Memorandum 04-01: Safe Water in Healthcare Premises-Part B: Operational Management; Department of Health: London, UK, 2016.

8. Centers for Disease Control and Prevention. Guidelines for preventing health-care associated penumonia, 2003. MMWR Morb. Mortal. Wkly. Rep. 2004, 53 (RR-3), 1-36.

9. Stout, J.E.; Muder, R.R.; Mietzner, S.; Wagener, M.M.; Perri, M.B.; DeRoos, K.; Goodrich, D.; Arnold, W.; Williamson, T.; Ruark, O.; et al. Role of environmental surveillance in determining the risk of hospital-acquired legionellosis: A national surveillance study with clinical correlations. Infect. Control Hosp. Epidemiol. 2007, 28, 818-824. [CrossRef] [PubMed]

10. Florentin, A.; Lizon, J.; Asensio, E.; Forin, J.; Rivier, A. Water and surface microbiologic quality of point-of-use water filters: A comparative study. Am. J. Infect. Control 2016, 44, 1061-1062. [CrossRef] [PubMed]

11. Kool, J.L.; Bergmire-Sweat, D.; Butler, J.C.; Brown, E.W.; Peabody, D.J.; Massi, D.S.; Carpenter, J.C.; Pruckler, J.M.; Benson, R.F.; Fields, B.S. Hospital characteristics associated with colonization of water systems by Legionella and risk of nosocomial Legionnaires' disease: A cohort study of 15 hospitals. Infect. Control Hosp. Epidemiol. 1999, 20, 798-805. [CrossRef] [PubMed]

12. Yu, V.L. Resolving the controversy on environmental cultures for Legionella: A modest proposal. Infect. Control Hosp. Epidemiol. 1998, 19, 893-897. [CrossRef] [PubMed]

(C) 2017 by the authors; licensee MDPI, Basel, Switzerland. This article is an open access article distributed under the terms and conditions of the Creative Commons Attribution (CC BY) license (http:/ / creativecommons.org/licenses/by/4.0/). 